\title{
Sistem Kendali Lampu Defect Dan Reject Berbasis Web Server Menggunakan Raspberrry Pi 3 Model B
}

\author{
Endang Supriyadi ${ }^{1}$, Maya Sofiana ${ }^{2}$, Surya Dwipangga ${ }^{3}$
}

\begin{abstract}
This research covers the design and construction of a Web-based Defect \& Reject Light Control Intelligent System with Raspberry $P i$ with the aim of detecting the quality conditions of manufactured goods at the final inspection section of PT. Suryaraya Rubberindo Industries. This system requires several components such as a Raspberry Pi 3 Microcontroller, Relays, mini filament LED lamps and several other supporting components. The design and construction of a Web-Based Defect \& Reject Light Control Intelligent System with the Raspberry Pi comes from experimental results, besides that it is also supported by several literary documents found in journals and reference books. This Intelligent Web-Based Defect \& Reject Light Control System with the Raspberry Pi uses a website design as an input to turn off or turn on a lamp. Two mini filament lamps are used as output components that are made like Signal lamps. Based on the results of the experiments conducted, the Web-Based Defect \& Reject Light Control Intelligent System with the Raspberry Pi can work quite well. When this system detects the condition of the production goods in a state that does not meet the specified company standards but has a low level of seriousness (defect), the system will give a signal for a yellow light with a value of 1 , whereas if the level of seriousness is high (reject) then the control system will give a signal to turn on the red light the value of the number 1 stored in the database.
\end{abstract}

Intisari- Penelitian ini meliputi racang dan bangun Sistem Cerdas Kendali Lampu Defect \& Reject Berbasis Web dengan Raspberry Pi dengan tujuan untuk mendeteksi kondisi kualitas barang produksi pada bagian final Inspection di PT. Suryaraya Rubberindo Industries. Sistem ini memerlukan beberapa komponen seperti Mikrokontroller Raspberry Pi 3, Relay, Lampu berjenis LED filamen mini dan beberapa komponen pendukung lainnya. Rancang Rangun Sistem Cerdas Kendali Lampu Defect \& Reject Berbasis Web dengan Raspberry Pi tersebut berasal dari hasil percobaan, selain itu didukung pula oleh beberapa literatur dokumen yang terdapat pada jurnal dan buku referensi. Sistem Cerdas Kendali Lampu Defect \& Reject Berbasis Web dengan Raspberry $\mathrm{Pi}$ ini menggunakan rancangan website sebagai input untuk mematikan atau menyalakan sebuah lampu. Dua buah lampu filamen mini digunakan sebagai komponen output yang dibuat seperti lampu Signal. Berdasarkan hasil percobaan yang dilakukan, Sistem Cerdas ini dapat bekerja dengan cukup baik. Ketika sistem ini mendeteksi kondisi barang produksi dalam keadaan tidak memenuhi standard perusahaan yang telah ditentukan akan tetapi memiliki tingkat keseriusan rendah (defect) maka sistem akan memberikan sinyal untuk lampu kuning bernilai angka 1 sedangkan jika tingkat keseriusan tinggi (reject) maka sistem kendali akan memberikan sinyal untuk menyalakan lampu merah bernilai angka 1 yang tersimpan pada database.

Kata Kunci- Defect, IOT, Kendali lampu, Kualitas, Raspberry Pi 3 Model B, Reject.

1,2,3 Institut Ilmu Sosial dan Manajemen STIAMI, Jl. TB Simatupang No.47 A, RW.5, Tj. Bar., Kec. Jagakarsa, Kota Jakarta Selatan, tlp: (021) 7820246; e-mail:, endangs2013@gmail.com, maya72sofiana@gmail.com, suryadwipangga4@gmail.com

\section{PENDAHULUAN}

Semakin bertambahnya popularitas internet, banyak bidang Di era globalisasi ini, aplikasi sistem dalam sebuah perusahaan menjadi hal yang sangat penting. Teknologi informasi yang semakin berkembang diharapkan dapat mendukung proses bisnis pada perusahaan. Semua kegiatan yang dilakukan dalam proses tersebut membuktikan bahwa kini teknologi informasi telah menjadi kebutuhan pokok dalam kehidupan manusia. Sistem infomasi dan teknologi informasi berperan untuk menghasilkan informasi yang sangat diperlukan setelah melalui pengolahan data yang ketat untuk pengambilan keputusan dalam menghadapi permasalahan yang kompleks.

Rancang bangun sistem kendali lampu defect dan reject berbasis web server pada bagian final inspection di PT. Suryaraya Rubberindo Industries bertujuan untuk membangun sebuah sistem kendali lampu yang dapat mendeteksi kondisi kualitas barang produksi. Sistem Kendali Lampu Defect dan Reject ini dilakukan pada suatu pekerjaan di bagian Final Inspection (QC). Proses kegiatan yang dilakukan pada bagian Final Inspection ini adalah dalam mengontrol kualitas barang masih menggunakan cara manual yaitu dengan cara melakukan pengecekan tanpa aplikasi khusus sehingga sulit untuk mendeteksi apakah produk yang telah dihasilkan sesuai dengan standard yang diinginkan atau tidak. Selain itu mengakibatkan kurangnya koordinasi dengan bagian lainnya yaitu bagian operator yang bertugas menerima pengembalian barang produksi defect dan reject. Diantaranya adalah sering sekali terjadi petugas operator sulit untuk membedakan barang defect atau reject sehingga secara tidak sengaja melakukan produksi barang tersebut tanpa kendali. Oleh karena itu perlu di bangun sebuah aplikasi kendali lampu defect dan reject pada sebuah bagian final inspection agar dapat membantu pekerjaan yang cepat dan akurat dalam menghasilkan produk berkualitas.

Sistem kendali lampu ini dapat membantu pengendalian mutu atau kualitas barang produksi yang dihasilkan oleh bagian lainnya. Sistem dapat mendeteksi kondisi setiap barang produksi yang telah dihasilkan sehingga akan meminimalisir barang gagal produksi dan juga tercipta koordinasi yang baik antara bagian satu dengan bagian lainnya seperti bagian inspeksi dengan bagian operator.

\section{TINJAUAN PUSTAKA}

Ada beberapa istilah yang perlu diketahui untuk memahami penulisan ini diantaranya adalah sebagai berikut :

A. Rancang Bangun Sistem informasi Kendali

1) Perancangan

Menurut Jogiyanto [1] pengertian perancangan yaitu sebagai berikut : Perancangan mempunyai 2 maksud, yaitu 
untuk memenuhi kebutuhan kepada pemakai sistem dan untuk memerikan gambaran yang jelas kepada pemrograman computer dan ahli-ahli teknik lainnya yang terlibat.

2) Kendali

Siklus kegiatan yang mencakup pengumpulan, peninjauan ulang, pelaporan, dan tindakan atas informasi suatu proses yang sedang diimplementasikan [2].

Dengan demikian pengertian rancang bangun merupakan kegiatan menerjemahkan hasil analisa ke dalam bentuk paket perangkat lunak kemudian menciptakan sistem tersebut atau memperbaiki sistem yang sudah ada.

B. Defect \& Reject

1. Defect

Defect merupakan keadaan dimana suatu produk dinyatakan gagal dalam mencapai persyaratan yang telah ditetapkan oleh perusahaan atau customer. Dengan tingkat keseriusan rendah. Produk dengan kategori defect ini masih dapat dilakukan perbaikan lagi (direpair) untuk mencapai persyaratan yang ditetapkan

2. Reject

Pengertian Reject menurut Kamus Besar Bahasa Indonesia yaitu barang atau jasa yang dibuat atau ditambah gunanya atau nilainya dalam proses produksi dan menjadi hasil akhir dari proses produksi itu.

\section{Web Server}

Web Server merupakan salah satu perangkat lunak yang berfungsi untuk menerima data permintaan yang dilakukan oleh http atau https melalui web client kemudian mengirimkannya kembali data dalam bentuk halamanhalaman dalam bentuk bahasa HTML [3].

Kumpulan halaman tersebut dapat dalam bentuk informasi teks, gambar diam atau gerak, animasi, suara, dan atau gabungan dari semuanya itu baik yangbersifat statis maupun dinamis yang membentuk satu rangkaian bangunan yang saling terkait dimana masing-masing dihubungkan dengan jaringan-jaringan halaman.

\section{Raspberry Pi 3 Model B}

Raspberry Pi 3 merupakan generasi ketiga dari keluarga Raspberry Pi.Raspberry Pi 3 memiliki RAM 1GB dan grafis Broadcomm VideoCore IV pada frekuensi clock yang lebih tinggi dari sebelumnya yang berjalan pada $250 \mathrm{MHz}$. Raspberry Pi 3 menggantikan Raspberry Pi 2 model B pada bulan Februari 2016 [4].

Kelebihan pada Raspberry Pi 3 mode B apabila dibandingkan dengan Raspberry Pi 2 yaitu:

1) $1.2 \mathrm{GHz}$ 64-bit quad-core ARMv8 CPU

2) $802.11 \mathrm{n}$ Wireless LAN

3) Bluetooth 4.1

Raspberry Pi 3 memiliki faktor bentuk yang identik dengan Raspberry Pi 2, dan memiliki kompatibilitas lengkap dengan Raspberry Pi 1 dan 2. Raspberry Pi 3 juga direkomendasikan untuk digunakan bagi mereka yang ingin menggunakan $\mathrm{Pi}$ dalam merancang suatu proyek yang membutuhkan daya yang sangat rendah.

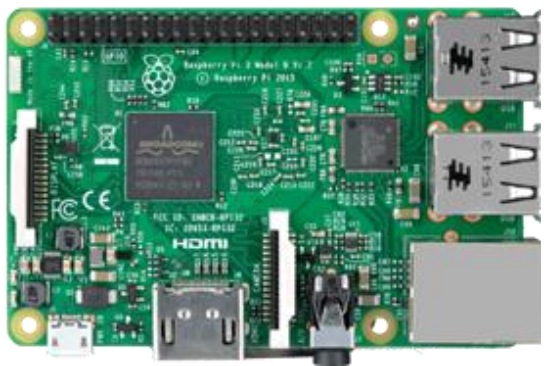

Gbr 1. Raspberry Pi 3

Adapun spesifikasinya sebagaimana yang terlihat pada tabel berikut ini :

TABEL I

SPESIFIKASI RASPBERRY PI 3

\begin{tabular}{ll}
\hline Processor & $\begin{array}{l}\text { Broadcom BCM2837 } \\
\text { Quad Core 1.2 GHz 64-Bit }\end{array}$ \\
\hline Arsitektur & ARM \\
\hline Sub-Arsitektur & ARM8 \\
\hline RAM & 1GB SDRAM 400 MHz \\
\hline Wireless & 802.1 In Wireless LAN \\
Adapter/Lan & \\
\hline Ethernet & 10/100 Mbps \\
\hline GPIO & 40 Pin \\
\hline USB & 4x USB 2.0 Port \\
\hline Display Port & HDMI (Full Size) \& DSI port \\
\hline Output Kamera & CSI Port Fleksible \\
\hline Memori Slot & Micro SD \\
\hline GPU & VideoCore IV 3D graphics core \\
\hline Bluetooth & Bluetooth 4.1 (built in), Bluetooth \\
\hline Sistem Operasi & Low Energy (BLE) \\
\hline & Debian GNU/Linux, Fedora, Arch \\
\hline
\end{tabular}

\section{E. Light Emitting Diode (LED)}

LED adalah komponen elektronika yang dapat memancarkan cahaya monokromatik ketika diberikan tegangan maju. LED merupakan keluarga Dioda yang terbuat dari bahan semikonduktor. Warna-warna Cahaya yang dipancarkan oleh LED tergantung pada jenis bahan semikonduktor yang dipergunakannya. LED juga dapat memancarkan sinar inframerah yang tidak tampak oleh mata seperti pada Remote Control TV ataupun Remote Control perangkat elektronik lainnya. Bentuk LED mirip dengan bola lampu yang kecil dan dapat dipasangkan dengan mudah ke dalam berbagai perangkat elektronika. Berbeda dengan Lampu Pijar, LED tidak memerlukan pembakaran filamen sehingga tidak menimbulkan panas dalam menghasilkan cahaya. Oleh karena itu, saat ini LED yang bentuknya kecil telah banyak digunakan sebagai lampu penerang dalam LCD TV yang mengganti lampu tube.

\section{Cara kerja LED}

Hampir sama dengan Dioda yang memiliki dua kutub yaitu kutub Positif (P) dan Kutub Negatif (N). LED hanya akan memancarkan cahaya apabila dialiri tegangan maju (bias forward) dari Anoda menuju ke Katoda.LED terdiri dari sebuah chip semikonduktor yang didoping sehingga menciptakan junction $\mathrm{P}$ dan $\mathrm{N}$. Yang dimaksud dengan 
proses doping dalam semikonduktor adalah proses untuk menambahkan ketidakmurnian (impurity) pada semikonduktor yang murni sehingga menghasilkan karakteristik kelistrikan yang diinginkan. Ketika LED dialiri tegangan maju atau bias forward yaitu dari Anoda (P) menuju ke Katoda (K), Kelebihan Elektron pada NType material akan berpindah ke wilayah yang kelebihan Hole (lubang) yaitu wilayah yang bermuatan positif ( $\mathrm{P}$ Type material). Saat Elektron berjumpa dengan Hole akan melepaskan photon dan memancarkan cahaya monokromatik (satu warna). LED yang memancarkan cahaya ketika dialiri tegangan maju ini juga dapat digolongkan sebagai Transduser yang dapat mengubah Energi Listrik menjadi Energi Cahaya.

2. Makna warna LED

LED telah memiliki beranekaragam warna, diantaranya seperti warna merah, kuning, biru, putih, hijau, jingga dan infra merah. Keanekaragaman Warna pada LED tergantung pada wavelength (panjang gelombang) dan senyawa semikonduktor yang dipergunakannya. Berikut ini adalah Tabel Senyawa Semikonduktor yang digunakan untuk menghasilkan variasi warna pada LED Tabel 2 Senyawa Semikonduktor LED disertai dengan panjang gelombang dan warna tertentu :

TABEL III

WARNA PADA LED

\begin{tabular}{|l|l|l|}
\hline Bahan Semikonduktor & Wavelength & Warna \\
\hline Gallium Arsenide (GaAs) & $850-940 \mathrm{~nm}$ & Infra Merah \\
\hline Gallium Arsenide Phosphide (GaAsP) & $630-660 \mathrm{~nm}$ & Merah \\
\hline Gallium Arsenide Phosphide (GaAsP) & $605-620 \mathrm{~nm}$ & Jingga \\
\hline Gallium Arsenide Phosphide Nitride (GaAsP:N) & $585-595 \mathrm{~nm}$ & Kuning \\
\hline Aluminium Gallium Phosphide (AlGaP) & $550-570 \mathrm{~nm}$ & Hijau \\
\hline Silicon Carbide (SiC) & $430-505 \mathrm{~nm}$ & Biru \\
\hline Gallium Indium Nitride (GalnN) & $450 \mathrm{~nm}$ & Putih \\
\hline
\end{tabular}

3) Tegangan Maju (Forward Bias) LED

Masing-masing Warna LED (Light Emitting Diode) memerlukan tegangan maju (Forward Bias) untuk dapat menyalakannya. Tegangan Maju untuk LED tergolong rendah sehingga memerlukan sebuah Resistor untuk membatasi Arus dan Tegangannya agar tidak merusak LED yang bersangkutan. Tegangan Maju biasanya dilambangkan dengan tanda VF.

TABEL III

TEGANGAN MAJU

\begin{tabular}{l|l|}
\hline Warna & Tegangan Maju @20mA \\
\hline Infra Merah & $1,2 \mathrm{~V}$ \\
\hline Merah & $1,8 \mathrm{~V}$ \\
\hline Jingga & $2.0 \mathrm{~V}$ \\
\hline Kuning & $2.2 \mathrm{~V}$ \\
\hline Hijau & $3,5 \mathrm{~V}$ \\
\hline Biru & $3,6 \mathrm{~V}$ \\
\hline Putih & $4,0 \mathrm{~V}$ \\
\hline
\end{tabular}

\section{F. Kualitas Produk}

Dalam bisnis suatu perusahaan menghasilkan suatu produk selain untuk mendapatkan profit. Selain profit juga untuk memenuhi kebutuhan bahkan kepuasan konsumen. Apabila konsumen puas maka profit perusahaan akan semakin meningkat. Seperti pendapat Kotler dalam Sembiring [5] produk adalah segala sesuatu yang ditatawarkan untuk memenuhi kebutuhan dan kepuasan komsumen Kualitas produk menjadi salah satu faktor yang harus fokus diperhatikan dalam kegiatan bisnis suatu perusahaan. Ketika kualitas produk terpenuhi maka akan menjadikan perusahaan tersebut menjadi yang terdepan bagi konsumen, karena konsumen merasa terpuaskan sesuai dengan harga yang dibayar oleh konsumen. Hal ini sejalan dengan pendapat Handoko dan Cahyo bahwa Kualitas Produk suatu kondisi penilaian dari sebuah barang sesuai dengan standar ukur yang telah ditetapkan. Sesuai dengan pendapat Sentono dalam Ahmadi [6] Kualitas produk adalah kondisi fisik, sifat, dan kegunaan suatu barang yang memberikan kepuasan konsumen secara fisik dan psikologis, sesuai dengan nilai uang yang dikeluarkan.

Kualitas produk harus dapat dengan rinci terukur. Sehingga akan dapat dilihat seberapa besar tingkatan kualitas barang tersebut. Diperlukan indikator dalam mengukur kualitas. Sehingga kehandalan dan ketelitian produk tersebut dapat terukur. Dalam hal ini ada beberapa indikator dalam pengukuran kualitas produk. Menurut Tjiptono dalam Anggraini [7] ada delapan dimensi kualitas produk:

1. Kinerja (Performance)

2. Ciri-ciri atau keistimewaan tambahan (Features)

3. Keandalan (Relaiability)

4. Kesesuaian dengan spesifikasi (Conformance)

5. Daya tahan (Durability)

6. Kemampuan diperbaiki (Service ability)

7. Estetika (Asthethic)

8. Ketepatan kualitas yang dipersepsikan (Perceived Quality)

Kualitas produk juga dipengaruhi oleh beberapa faktor. Faktor-faktor yang mempengaruhi kualitas produk menurut Assaury dalam Sembiring [5] adalah sebagai berikut:

1. Fungsi suatu produk

Fungsi untuk apa produk tersebut digunakan atau dimaksudkan.

2. Wujud luar

Faktor wujud luar tidak hanya terlihat dari bentuk tetapi warna dan pembungkusnya.

3. Biaya produksi yang bersangkutan

Biaya untuk peroleh suatu barang, misalnya harga barang serta biaya barang sampai kepada pembeli.

\section{METODE PENELITIAN}

Tahapan pengembangan sistem yang penulis lakukan adalah menggunakan konsep System Development Life Sycle (SDLC) dengan perspektif model waterfall sebagai berikut [8] :

1. Analisa kebutuhan sistem

Berdasarkan hasil analisa yang telah dilakukan, perlu dirancang sistem kendali yang bertujuan untuk mendeteksi 
barang produksi dalam kondisi defect atau reject. Hal tersebut dilakukan pada sub bagian inspector dan operator di PT. Surya Raya Rubberindo Industries. Status kondisi barang akan ditandai dengan kode lampu kuning atau merah.

2. Design

Perancangan sistem yang penulis lakukan menggunakan model UML (Unified Model Languages) terdiri dari use case diagram, activity diagram, sequence diagram, class diagram untuk menggambarkan interaksi sistem dengan user.

3. Coding

Pada penelitian ini menggunakan bahasa pemrograman javascript yang tertanam pada Raspberry Pi 3 Model B yang digunakan untuk menterjemahkan design aplikasi sistem kendali tersebut.

4. Testing

Setelah dilakukan pencodingan sesuai dengan rangkaian design yang telah digambarkan dengan menggunakan konsep UML, langkah berikutnya melakukan proses uji coba sistem kendali berjalan sesuai dengan yang diharapkan yaitu system kendali dapat mendeteksi kondisi barang produksi defect atau reject.

5. Maintance

Pemeliharaan pada aplikasi system kendali bergantung dari permasalahan pada beberapa fungsi sistem kendali tersebut. Perbaikan dilakukan terus menerus dengan cara melakukan observasi pada semua fungsi kinerja sistem. Selain itu perbaikan perangkat dilakukan secara berkala sesuai dengan durasi pemakaian. Sebab setiap peralatan pasti memiliki batas toleransi pemakaian.

\section{PEMBAHASAN DAN HASIL}

A. Proses sistem berjalan

Proses sistem yang sedang berjalan pada saat sebelum dibuat sistem kendali dapat digambarkan pada gambar flowchart

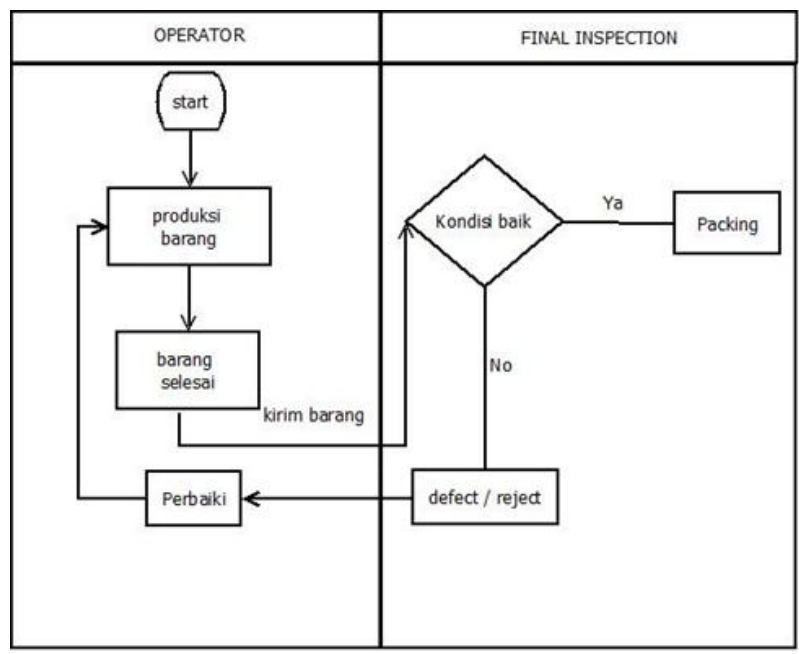

Gbr 2. Flowchart Sistem Berjalan
Sistem berjalan dimulai dari bagian Operator yang bertanggungjawab untuk memproduksi barang produksi, barang yang telah selesai dikerjakan kemudian dikirim ke bagian final inspection untuk dilakukan pengecekan barang apakah kondisi baik atau tidak, jika baik maka akan dilanjutkan proses selanjutnya yaitu packing. Akan tetapi jika statusnya Reject / Defect dari hasil pengecekan maka bagian final inspection akan menginformasikan kepada bagian operator untuk segera memperbaiki barang tersebut.

\section{B. Perancangan Sistem Informasi Kendali Lampu Defect dan} Reject

1. Usecase Diagram

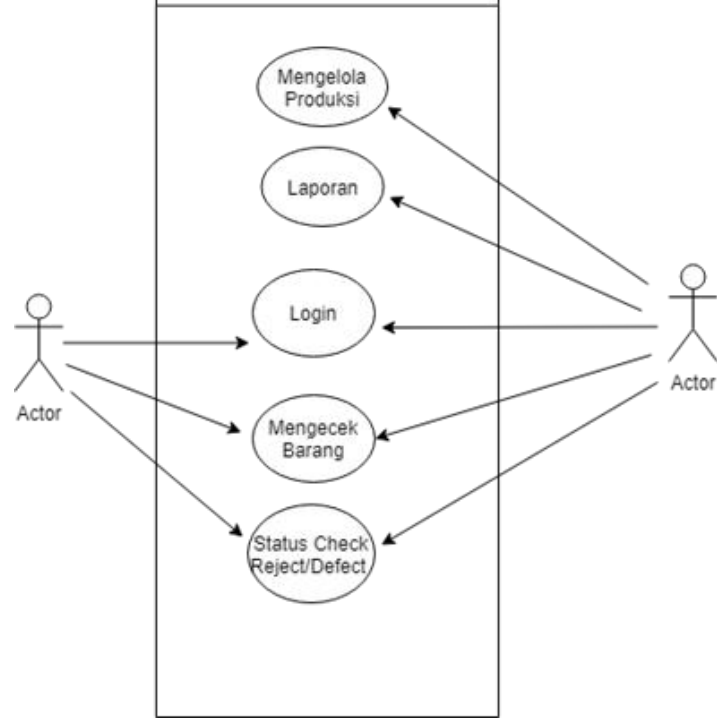

Gbr 3. Use Case Diagram sistem kendali

2. Activity Diagram

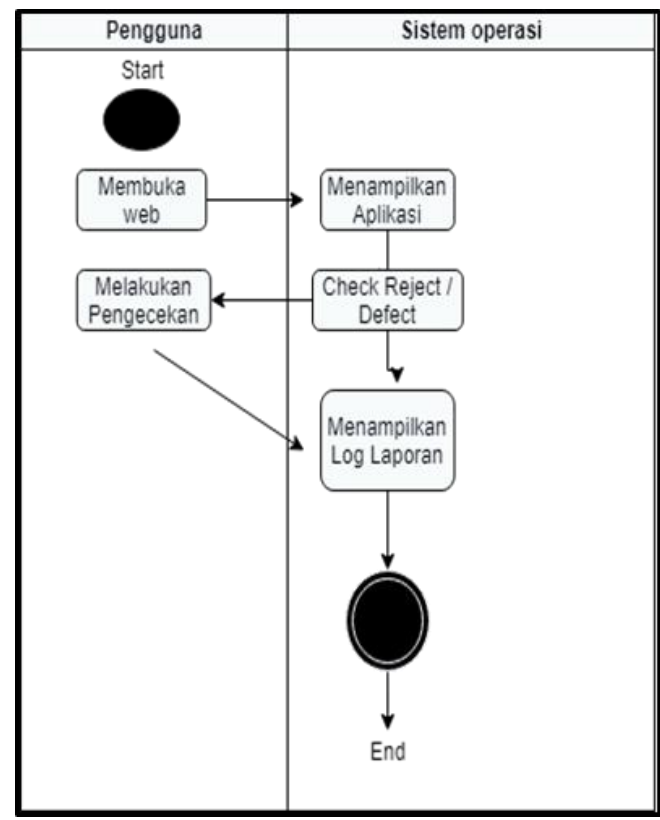

Gbr 4. Activity Diagram 


\section{Class Diagram}

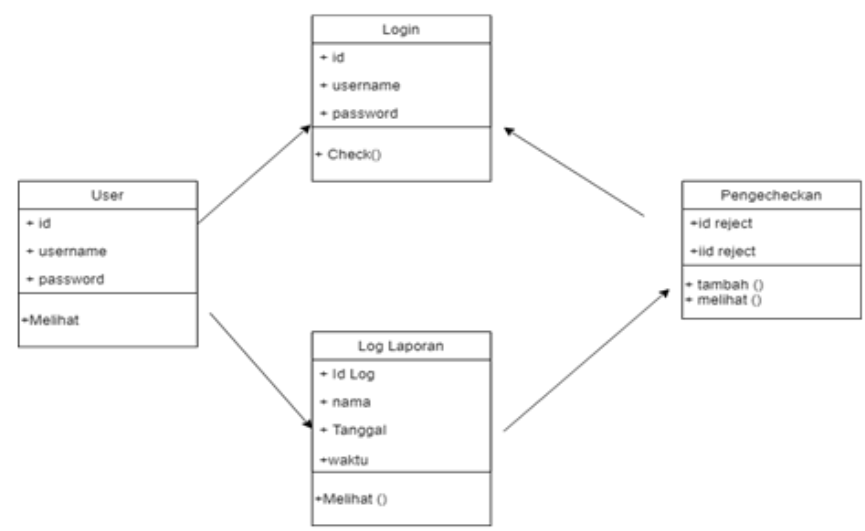

Gbr 5. Class Diagram

4. Sequence Diagram

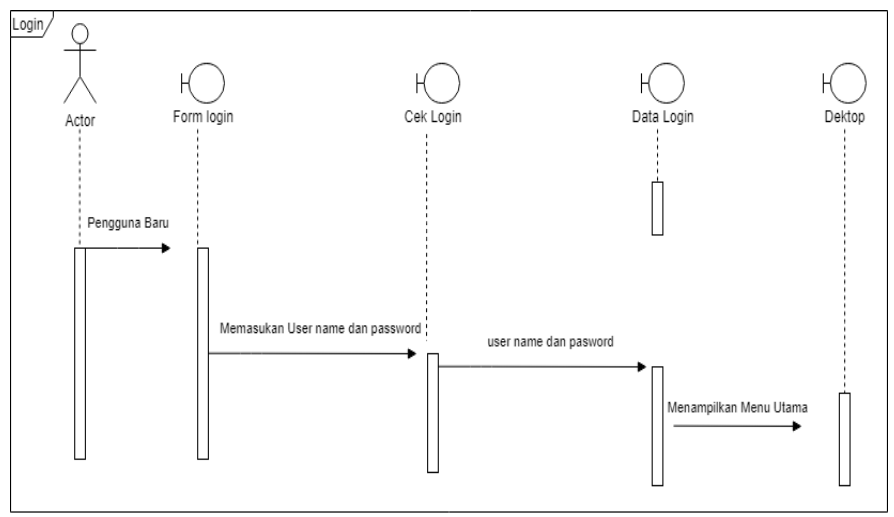

Gbr 6. Sequence Diagram

C. Uji coba program aplikasi kendali

1. Tahap persiapan perangkat

Memeriksa keseluruhan kabel atau wiring untuk memastikan apakah masing-masing fungsi kabel sudah sesuai dengan port yang disambungkan agar tidak terjadi arus pendek (short).Penyesuaian terhadap tegangan juga perlu dilakukan agar tidak terjadi kekurangan daya untuk komponen utama Raspberry Pi 3 Model B. Da Pada alat ini diperlukan tegangan minimal sebesar 5v dengan menggunakan Adaptor Raspberry, agar Raspberry Pi dapat beroperasi dengan optimal.

2. Running javascript

Sebelum pengoperasikan alat, diperlukan untuk mengaktifkan program javascript terlebih dahulu yang tertanam pada Raspberry Pi 3 Model B . Program tersebut diaktifkan untuk membuka website untuk input dan mengaktifkan lampu yang di gunakan.

3. Running aplikasi Raspberry Pi Mengaktifkan Raspberry Pi dan tunggu hingga tampilan homescreen Raspbian muncul.

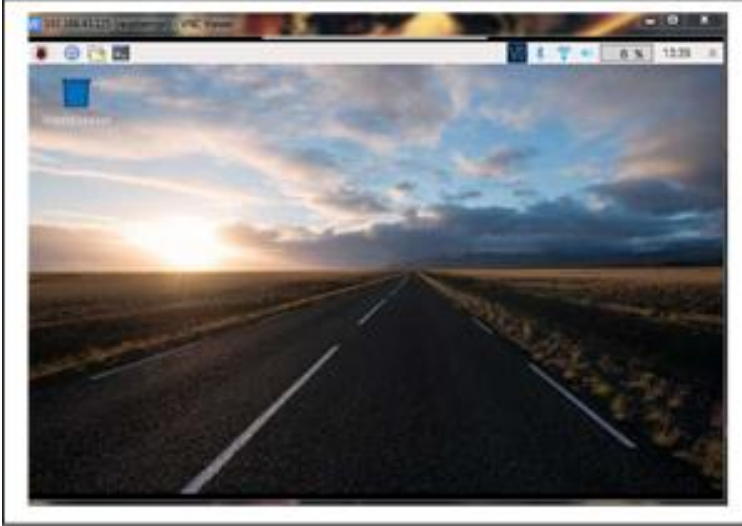

Gbr 7. Tampilan Homescreen Raspbian Pi

4. Aktifkan program diterminal melalui alamat address 192.168.43.125: 8000/

Ketikkan perintah untuk mengaktifkan program diterminal seperti pada tampilan berikut lalu setelah aktif akan muncul server starts - 192.168.43.125 : 8000/. Kemudian Copy Ip nya ke Goole untuk menuju pengaktifan lampu

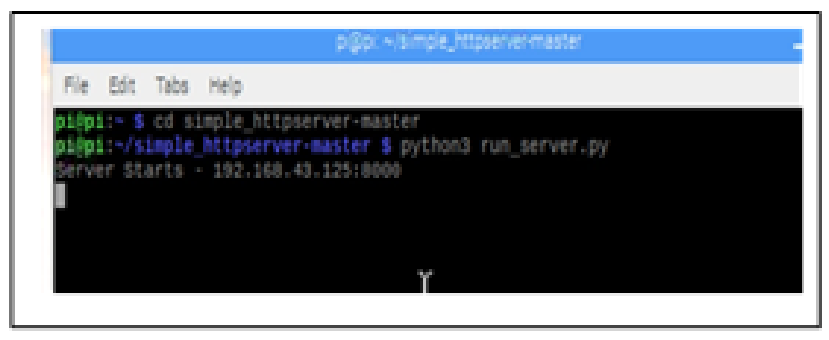

Gbr 8. kondisi web server aktif

5. Tahap pengoperasian sistem kendali

Pertama adalah membuka website yang sebelumnya sudah terkonfigurasi tanpa ada masalah atau error sedikit pun seperti yang sudah dijelaskan pada poin-poin diatas. Selanjutnya Rancangan sudah siap digunakan dan dikontrol dari jarak jauh melalui jaringan internet.

6. Testing kondisi lampu

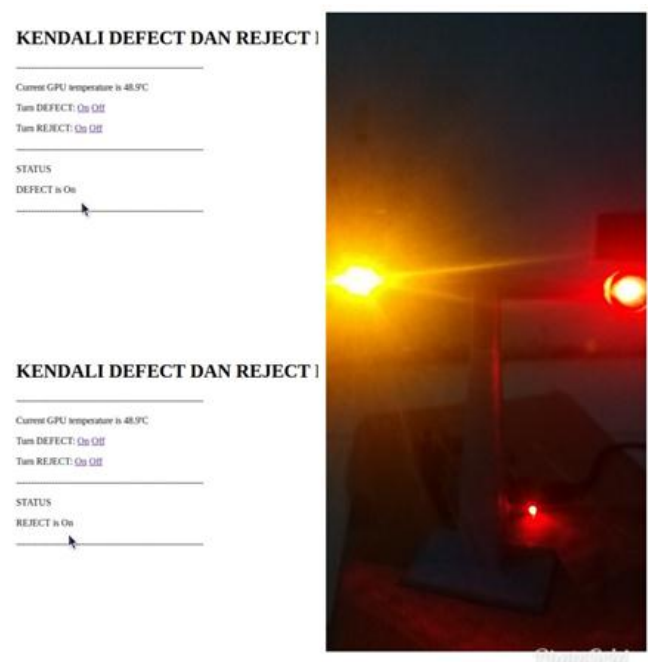

Gbr 9. Uji coba kondisi 2 lampu 
7. Tes kondisi lampu reject ( merah )

Uji coba selanjutnya adalah menyalakan salah satu lampu Reject (Merah). Contoh lampu yang akan dinyalakan adalah lampu 1 / Lampu Reject.
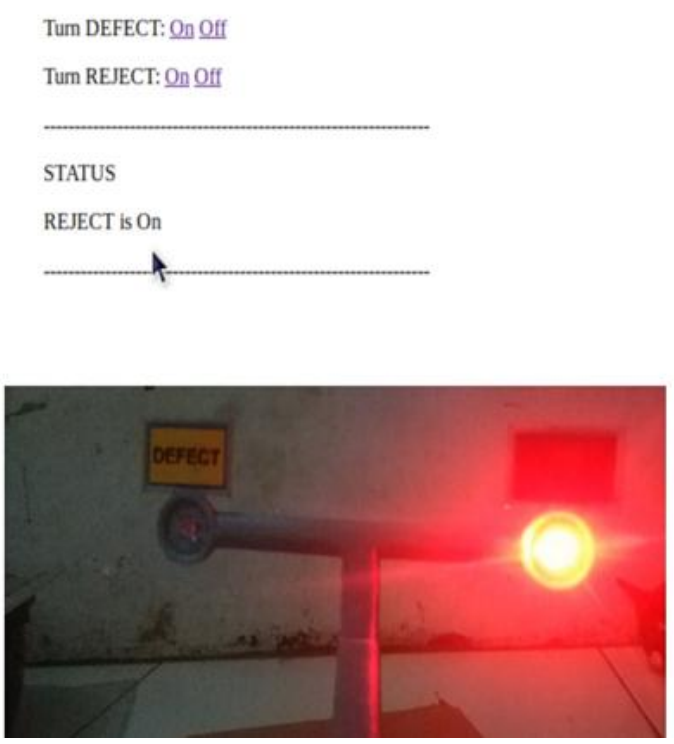

Gbr 10. Uji coba lampu reject

8. Test kondisi lampu defect

Selanjutnya adalah menyalakan salah satu lampu Defect (Kuning). Contoh lampu yang akan dinyalakan adalah lampu 2 / Lampu Defect.

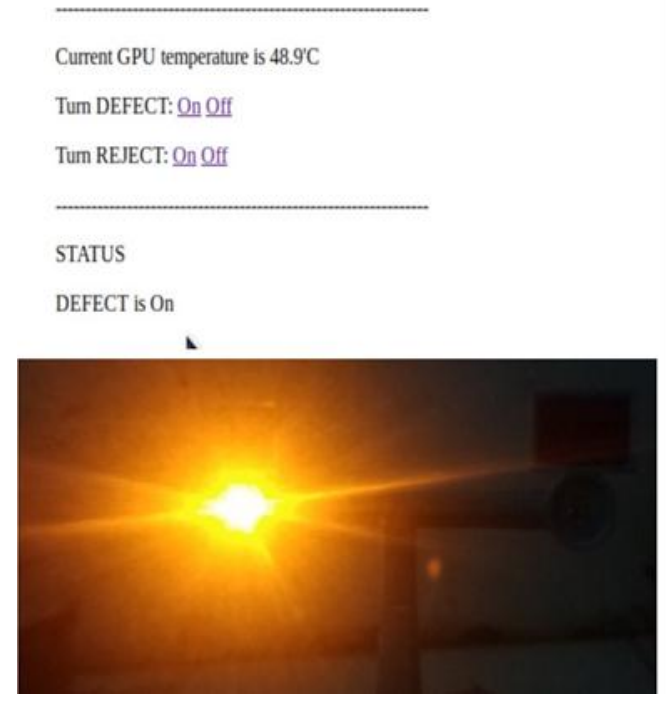

Gbr 11. uji coba kondisi lampu defect

D. Analisa Hasil

Uji coba running aplikasi dalam kondisi online dan offline serta jarak.
TABEL IV

RUNNING APLIKASI MODE OFFLINE

\begin{tabular}{cccc}
\hline Lampu & Jarak & ResponseTime & Status \\
\hline $\begin{array}{l}\text { Lampu } \\
\text { Reject }\end{array}$ & $4 \mathrm{~m}$ & 0,005 detik / $5 \mathrm{~ms}$ & Menyala \\
\hline $\begin{array}{c}\text { Lampu } \\
\text { Defect }\end{array}$ & $6 \mathrm{~m}$ & $0,004 \mathrm{detik} / 4 \mathrm{~ms}$ & Menyala \\
\hline $\begin{array}{l}\text { Lampu } \\
\text { Reject }\end{array}$ & $12 \mathrm{~m}$ & $0.010 \mathrm{detik} / 10 \mathrm{~ms}$ & Menyala \\
\hline $\begin{array}{l}\text { Lampu } \\
\text { Defect }\end{array}$ & $13 \mathrm{~m}$ & 0.009 detik / $9 \mathrm{~ms}$ & Menyala \\
\hline
\end{tabular}

TABEL V

RUNNING APLIKASI MODE ONLINE

\begin{tabular}{cccc}
\hline Lampu & Jarak & ResponseTime & Status \\
\hline $\begin{array}{c}\text { Lampu } \\
\text { Reject }\end{array}$ & $4 \mathrm{G}$ & 1,42 detik / 1420ms & Menyala \\
\hline $\begin{array}{c}\text { Lampu } \\
\text { Defect }\end{array}$ & $4 \mathrm{G}$ & $1,68 \mathrm{detik} / 1680 \mathrm{~ms}$ & Menyala \\
\hline $\begin{array}{c}\text { Lampu } \\
\text { Reject }\end{array}$ & $3 \mathrm{G}$ & 1,61 detik / 1610ms & Menyala \\
\hline $\begin{array}{l}\text { Lampu } \\
\text { Defect }\end{array}$ & $3 \mathrm{G}$ & 1,44 detik / 1840ms & Menyala
\end{tabular}

Berdasarkan analisa pada tabel IV dan V, dapat diketahui bahwa jarak antara user dengan rancangannya tidak berpengaruh pada keterlambatan waktu proses. Namun jaringan atau sinyal yang dimiliki user dan hotspot sangat berpengaruh. Hal ini dikarenakan untuk mengakses rancangan dalam kondisi online harus memiliki jaringan dan sinyal yang kuat agar dapat mengakses rancang bangun dengan stabil. Selain sinyal dan jaringan internet, jarak antara rancangan dengan hotspot pun sedikit berpengaruh dan dipastikan akan terjadi keterlambatan waktu proses.

E. Report hasil uji coba

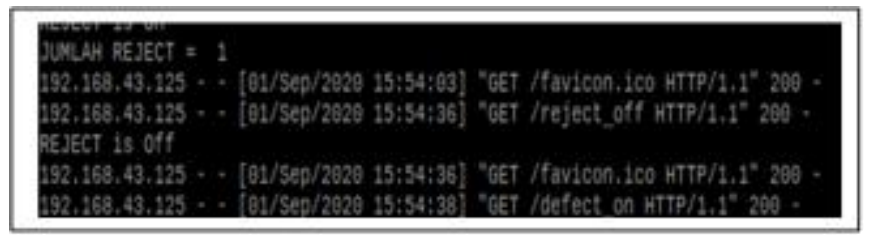

Gbr 12. Report deteksi barang reject

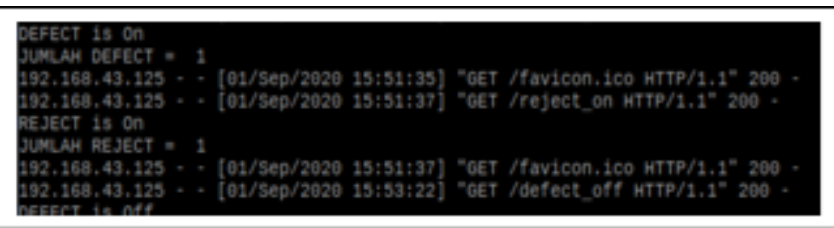

Gbr 15. Report deteksi barang defect

\section{KESIMPULAN}

Rancangan perangkat sistem kendali ini dapat dikendalikan dari mana saja melalui link url karena sudah berbasis IOT (Internet Of Things) selama Raspberry Pi 
sebagai komponen utama terhubung ke router atau device yang terkoneksi dengan jaringan internet. Ketika menggunakan localhost/offline jarak antara rancangan sistem kendali dan router atau device,fungsi sistem kendali tidak berpengaruh besar, jadi selama sistem kendali dan device terhubung lampu dapat dikendalikan secara realtime. Namun ketika sistem kendali dioperasikan secara online, maka jarak dan sinyal sedikit berpengaruh sehingga terjadi keterlambatan waktu proses pada sistem operasi sistem kendali.

\section{UCAPAN TERIMA KASIH}

Alhamdulillah puji syukur, penulis panjatkan kehadirat Allah SWT, yang telah melimpahkan rahmat dan karunianya, sehingga penulis dapat menyelesaikan penelitian ini dengan lacar tanpa kendala apapun, terutama pada bagian operator dan final inspection PT. Surya Raya Rubberindo Industries. Dan tidak lupa pula kami ucapkan kepada tim editor serta penerbit dari tim jurnal antar bangsa yang telah memberikan kesempatan pada penulis untuk menerbitkan penelitian ini pada jurnal STMIK Antar Bangsa.

\section{REFERENSI}

[1] Jogiyanto, Analisis dan Desain Sistem Informasi Pendekatan Terstruktur Teori dan Praktek Aplikasi Bisnis, yogyakarta: Andi Offset, 2005.

[2] m. corps, "Design, Monitoring and Evaluation Guidebook," [Online].

Available: http://www.mercycorps.org/sites/default/files/file1157150018.p df. [Accessed 12 mei 2016].

[3] A. Azikin, Debian, Bandung: Informatika Bandung, 2011.

[4] F. F. B. W. P. Pradea Andika Alam, "Rancangan Sistem Pengaman Menggunakan RASPBERRY PIDAN IP Kamera Guna Meningkatkan Keamanan Pada Shelter DVOR PERUM LPPNPI Cabang Madya YOGYAKARTA,” Jurnal Ilmiah Aviasi Langit Biru, vol. 11, p. $1:$ 68, 2018.

[5] S. K. Sembiring, "Pengaruh Kualitas Produk dan Kualitas Pelayanan Terhadap Kepuasan Pelanggan dalam Membentuk Loyalitas Pelanggan,” Jurnal Administrasi Bisnis (JAB), vol. 15, pp. 1-10, 2014.

[6] Ahmad, "Six Sigma DMAIC Sebagai Metode Pengendalian Kualitas Produk Kursi pada UKM," Jurnal Integrasi Sistem Industri, vol. 6, 2016.

[7] H. S. Anggraini, “ Pengaruh Kualitas Produk, Harga Terhadap Keputusan Pembelian,” Jurnal Administrasi Bisnis, vol. 73, pp. 118-124, 2019.

[8] D. Abdullah, Merancang Aplikasi Perpustakaan Menggunakan SDLC, Lhokseumawe: Sefa Bumi Aksara, 2017.

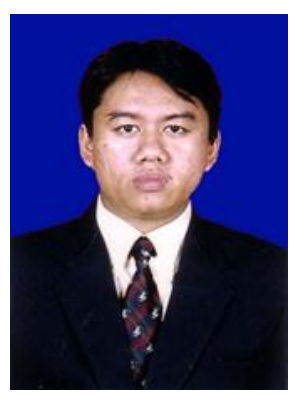

Endang Supriyadi, lahir di Jakarta, 14 Nopember 1974. Memperoleh gelar Diploma III (D3), Jurusan Manajemen Informatika Universitas Gunadarma Depok, lulus tahun 1998 dan memperoleh gelar Sarjana Al-Quran (SQ) dan gelar Sarjana Agama (S.Ag) Fakultas Tarbiyah Jurusan Pendidikan Agama Islam di Institut Perguruan Tinggi Ilmu Al-qur'an Jakarta ( IPTIQ ) lulus tahun 1999. Memperoleh gelar Magister Komputer (M.Kom) Program Pasca Sarjana Magister Ilmu Komputer Konsentrasi E-Business STMIK Nusa Mandiri Jakarta, lulus tahun 2015. Pernah mengajar di STMIK Nusa Mandiri Jakarta, STIMA IMMI, STMIK Triguna Utama dan saat ini aktif mengajar di beberapa perguruan tinggi swasta lainnya : Politeknik LP3I Jakarta Kampus Depok, Institut Ilmu Sosial dan Manajemen STIAMI, Insititut Bisnis dan Ilmu Komputer ( IBIK57 ) Kosgoro serta menjadi anggota tim asesor LSP Politeknik LP3I Jakarta untuk kompetensi bidang ilmu komputer. Pendiri lembaga kursus komputer LKP-PROTECH Depok ( WWW.LKPPROTECH.COM ) dan pendiri cadastrwwet wilayah pancoranmas Depok. Selain itu aktif pula menulis buku panduan komputer aplikasi perkantoran dan artikel ilmiah yang pernah di publish dintaranya : Metode SVM Berbasis PSO untuk Meningkatkan Prediksi Ketepatan Waktu Kelulusan Mahasiswa, Analisa Web untuk Memahami Perilaku Konsumen Online Studi Kasus "Store Steam Powered" dll.

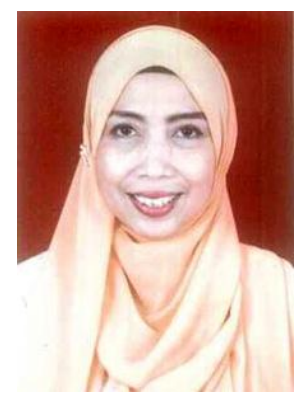

Maya Sofiana. Surabaya, 13 Mei 1972. Memulai pendidikan di Sekolah Menengah Atas Negeri (SMAN) 52, Jakarta lulus tahun 1991. Kemudian melanjutkan ke Ikip Jakarta d/h Universitas Negeri Fatultas Ilmu sosialProgram Studi Administrasi Perkantoran Jakarta tahun 1992 dan lulus tahun 1997. Lalu tahun 1998 melanjutkan Strata Dua (S2) Magister Manajemen di Universitas Jayabaya Jakarta lulus tahun 2000. Pernah bekerja di PT Aditya Apprasial Bhakti tahun 2000. Kemudian Tahun 2003. bekerja di Yayasan Widya Bhakti. Saat ini mengajar di beberapa kampus swasta Institut Ilmu Sosial dan Manajemen Stiami, Poltek LP3I Jakarta dan memberikan pelatihan Perkantoran karyawan di beberapa instansi Kemendikbud, dan Kementerian Pertahanan RI. Paper jurnal yang pernah dipublikasikana adalah sebagai berikut: Pelaksanaan Manajemen K3 pada PT Adyawinsa T 7 E di Jakarta (Majalah Ilmiah Bijak), Pelatihan Pengenalan Aplikasi Perkantoran ( Typing Master dan Word) bagi Remaja Karang Taruna RT 4 Kelurahan Cinere Kecamatan Cinere Depok Jawa Barat (Jurnal Komunitas-Jurnal Pengabdian Kepada Masyarakat), Prosedur Production Control pada PT Astra Honda Motor Jakarta (Jurnal Abiwara-Jurnal Vokasi Administrasi Bisnis), Studi Komparasi Kepuasan Pasien BPJS dan Non BPJS pada Mutu Pelayanan Pendaftaran Puskesma Johar Baru Jakarta Pusat (Jurnal Abiwara-Jurnal Vokasi Administrasi Bisnis), Green Office Concept Assesment in The Council Show The Office Care (Majalah Ilmiah Bijak).

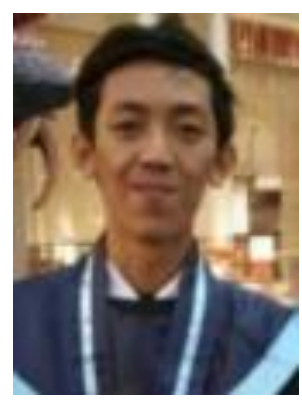

Surya Dwipangga. Lahir di Bogor, 14 Maret 1998. Meraih gelar Diploma D3 Prodi Manajemen Informatika, konsentrasi Informatika Komputer di Politeknik LP3I Jakarta tahun 2020. Saat ini bekerja di perusahaan swasta. 